Article

\title{
Exploring On-Site Safety Knowledge Transfer in the Construction Industry
}

\author{
Ying-Hua Huang $1, *(-)$ and Tzung-Ru Yang ${ }^{2}$ \\ 1 Department of Civil and Construction Engineering, National Yunlin University of Science and Technology, \\ Yunlin 640, Taiwan \\ 2 Engineering Department, Yuan Tay Construction Co., Ltd., Kaohsiung 807, Taiwan \\ * Correspondence: huangyh@yuntech.edu.tw
}

Received: 21 October 2019; Accepted: 13 November 2019; Published: 15 November 2019

check for updates

\begin{abstract}
A primary cause of occupational accidents is on-site workers not having proper or even adequate safety knowledge and awareness, leading to them failing to employ safety measures, equipment, or behavior to protect themselves. The complexity of construction projects and changes in organizational personnel complicate the safety knowledge transfer process. Therefore, to reduce occupational accidents in the construction industry, this study explored the on-site safety knowledge transfer process as well as its relationship with a safe working environment; it did this to understand the associations between various constructs in the process, which could be used as a reference for management personnel to promote on-site safety education and behaviors. This would allow safety knowledge to be learned and practiced by on-site workers, changing their unsafe behaviors and creating a safe on-site work environment. This study used structural equation modeling to empirically study the relationship between various constructs during safety knowledge transfer on a construction site. The results revealed that an excellent safety knowledge transfer environment can lead to favorable safety behavior as well as safety knowledge application and inspiration of on-site workers, which would affect their safety behaviors. More satisfactory safety behaviors of on-site workers could produce a safer working environment on the construction site. Moreover, although safety application and inspiration do not directly affect the safety of a work environment, they do so indirectly through safety behaviors.
\end{abstract}

Keywords: knowledge transfer; safety behavior; safety management; construction site; structural equation modeling (SEM)

\section{Introduction}

The construction industry is characterized by one-time products, multi-level subcontracting, and complex staffing. Different construction stages usually have different staffing. Labor safety issues occur easily because of the uncertain labor source demands. According to statistics compiled by Taiwan's Ministry of Labor, the occupational injury death rate per thousand was 0.113 (excluding traffic accidents) for the construction industry in Taiwan in 2018, which was the highest amongst all industries; furthermore, the occupational fatal injury rate in the construction industry per thousand (including morbidity, disability, and death) was 9.385, which was also the highest amongst all industries [1]. Over the years, occupational accident analysis of Taiwan's construction industry has shown that one of the most common accidents in public works is workers falling without personal protective equipment. In private construction projects, accidents are caused by employers not providing personal protective equipment for workers or workers not using it or ignored warning signs when preparing, repairing, or finishing work on a ladder, platform, floor surface, or steel component [2]. Occupational accidents are mostly caused by noncomplying facilities, improper personal protective equipment, unsafe guardrails 
and covers, or the absence of protective measures [3]. Relevant studies on construction site safety performance and assessment have noted that workers have low safety awareness [4,5], inadequate safety knowledge and training [6,7], and unsafe practices [8]. A review of major occupational accidents and relevant studies reveals some of the main causes of occupational accidents are workers on construction sites lacking proper personal safety knowledge and failing to take appropriate safety measures, equipment, or actions to protect themselves.

The causes of occupational accidents are complicated by numerous events with causal relationships. However, if on-site workers do not possess correct safety concepts, the number of accidents in the construction industry cannot be reduced. Approximately $90 \%$ of accidents are caused by unsafe environments and behaviors [8-10]. Person, behavior, and environment are three dynamic and interactive factors, and changes in any one of them will affect the other two [11]. How to ensure on-site workers learn and practice safety knowledge to correct unsafe behaviors and create a safe construction environment forms the basis for reducing occupational accidents in the construction industry.

Knowledge involves commitment and action [12]. The knowledge transfer conceptual model developed by Gilbert and Cordey-Hayes [13] emphasized that knowledge transfer is a dynamic process that must be assimilated into members of an organization. That is, workers are considered to truly acquire relevant knowledge after they apply it to the daily activities of their organization, which is reflected in changes in personal cognition and behavior. According to the high occupational injury rates in the construction industry, a gap exists between the education of on-site safety knowledge and the safety awareness and behaviors of on-site workers. Because of complex construction projects and changes in organizational personnel, the process of transferring safety knowledge becomes more complex.

This study aimed to identify both of the on-site safety knowledge transfer processes and the relationship between safety knowledge transfer and the safety of on-site work environments. The results of this study can be used as a good reference when the constructors plan to establish specific on-site safety education and to promote essential working environment safety. This study has the following two objectives:

1. To develop a safety knowledge transfer model and to identify on-site safety knowledge transfer mechanisms.

2. To explore the correlation between on-site safety knowledge transfer and the safe working environment.

The remainder of this paper is organized as follows. Section 2 presents a literature review on constructs required for construction worker's safety knowledge transfer. Section 3 presents the research model and research hypotheses. Section 4 presents the research methodology. Section 5 explains the design of the questionnaire and survey process. Sections 6 and 7 describe how structural equation modeling (SEM) was used to verify the relevance of knowledge transfer to a safe working environment and present results and discussion. Finally, Section 8 presents the study's conclusions.

\section{Literature Review}

\subsection{Knowledge Transfer}

Knowledge is the result of information processing, which involves rearranging, quantifying, qualifying, grouping, and learning [14]; these processes allow people to make meaningful connections between information and actions based on responses to information [15]. Knowledge is not only stored in documents and storage systems for an organization, but also in the processes, implementation, and specifications of daily work [16]. Knowledge can be divided into tacit knowledge and explicit knowledge. Tacit knowledge refers to subjective and substantive knowledge that cannot be expressed in words or sentences. It is personal, difficult to formalize, and deeply embedded in individual actions and experiences, personal ideals, values, and inner feelings; by contrast, explicit knowledge refers 
to objective and metaphysical knowledge that can be expressed in words and numbers. It can be conveyed in formal and institutionalized language, and easily communicated and shared using specific materials, scientific formulas, standardized procedures, and general principles [17,18]. Both tacit and explicit knowledge are learned through the continuous flow of knowledge, such as drawing on the personal experiences of friends and family, observing and imitating the states of others, knowledge being passed from teachers to students in schools, knowledge being imparted from senior staff to junior staff at a company, and companies holding meetings to announce changes in internal rules. All of these are knowledge transfer processes.

Szulanski [19] defined knowledge transfer as the flow of knowledge among organizational members; that is, the routine exchange of knowledge between knowledge providers and recipients for the operation of individual skills and social systems. Davenport and Prusak [16] emphasized that this process involves transmission and absorption, where transmission refers to knowledge being transmitted to potential recipients and absorption refers to people absorbing accepted knowledge. Knowledge transfer fails if the knowledge is not absorbed by recipients; this reflects the importance of interaction between knowledge providers and recipients, because knowledge can only be transferred when both parties are willing to share and receive the knowledge, respectively [20]. In addition, Wiig [21] defined knowledge transfer from a systematic point of view. He asserted that knowledge transfer includes actions such as knowledge acquisition, organization, structural reconstruction, storage, memory, and reassembly for deployment and dissemination. Organizations must provide basic construction capabilities that support knowledge transfer and create incentives to motivate employees, teams, departments, and business units to work together toward mutual goals.

According to a literature review and actual surveys, Gilbert and Cordey-Hayes [13] compiled their knowledge transfer conceptual framework into a five-step model to illustrate the connotations of knowledge transfer.

1. Acquisition: The first step in knowledge transfer requires knowledge acquisition, which can be achieved through acquiring knowledge from past experiences of work processes or environments, and discussions, as well as through obtaining new knowledge from personal sharing.

2. Communication: Organizations must develop communication mechanisms in written and verbal forms, and must be aware of and eliminate obstacles that hinder communication within the organization to ensure that knowledge can be effectively transferred.

3. Application: The application of acquired and communicated knowledge can ensure it is transferred and retained within the organization; knowledge application enables all members of an organization to learn, apply, and pass on knowledge.

4. Acceptance: The most essential key to knowledge transfer is acceptance. Once knowledge is applied, it must be accepted by individuals for consistent application as well as be assimilated into core daily activities.

5. Assimilation: Another crucial key to knowledge transfer is assimilation, which is the result of the acceptance of knowledge application. The essence of assimilation refers to the process of knowledge creation, including the cumulative learning process, which demonstrates individuals' changes in cognition and behavior that enable them to practically apply the knowledge they have acquired to daily activities of their organization.

\subsection{Safety Knowledge}

In terms of construction-safety knowledge, explicit knowledge exists in the form of accident records, mandated safety rules and regulations, and best practices [22], whereas tacit knowledge mainly relies on workers' personal experience of safety engineering [23]. Safety climate research has suggested that safety knowledge is a critical determinant of safety behavior or may act as a mediator between safety climate and safety performance [24]. Improving the safety knowledge of workers helps to reduce the risk of accidents [25]. 
Safety knowledge, whether explicit or tacit, is mostly scattered and fragmented. Thus, relevant research has focused more on safety knowledge management and learning technologies. Zhang et al. [22] proposed a construction-safety knowledge ontology to formalize safety management knowledge, as well as explored its connection with building information modeling to enable more effective safety-knowledge inquiries. Taher et al. [26] integrated developed earthwork safety regulation knowledge with an earthwork ontology to bridge the gap between high-level safety regulations and task-level instructions. Le et al. [27] proposed an online social virtual reality system framework, which allowed students to perform role-playing, dialogic learning, and social interactions for construction health and safety education. Li et al. [25] presented Internet of things applications for knowledge exchange and safety awareness in construction. Although researchers have mentioned the importance of safety knowledge in safety performance, relatively little is known about the mechanism of safety knowledge transformation.

\section{Research Model and Hypotheses}

\subsection{Constructing a Safety Knowledge Transfer Model}

This study referenced the knowledge transfer concept proposed by Gilbert and Cordey-Hayes [13] and summarized relevant studies on construction safety to establish a model for developing on-site safety knowledge transfer, as well as investigated the correlation between safety knowledge transfer and safe work environments. Following the concepts proposed by Gilbert and Cordey-Hayes [13], the on-site safety knowledge transfer model is described as follows:

1. Acquisition of safety knowledge:

According to the channels of learning and acquiring safety knowledge proposed by scholars, this study summarized the concepts of safety knowledge acquisition into safety training, safety leadership, and self-learning. Safety training equips workers with the skills required to recognize and manage hazards [28]. It can improve the safety climate and its effect on enhancing worker's safety attitudes, perceptions, and behaviors. Organizations can influence the safety performance of their workers by teaching and training them in safety behaviors and attitudes [24,29]. Blair [30] emphasized that supervisors must provide education, training, and resources to ensure that workers are effectively developed and prepared to contribute to safety. Hofmann and Morgeson [31] argued that the interaction between supervisors and workers can influence an organization's safety communication and worker accidents, which they defined as safety leadership. Conducting safety leadership will drive workers to demonstrate safe behavior [32]. Through enabling workers to understand policies and rules in the workplace, promoting an open and trustworthy relationship with workers, increasing worker rights and responsibilities for safety performance, and taking the initiative to conduct safety-related activities, supervisors can establish a safety paradigm, thereby enhancing workers' safety in the workplace [33]. In addition, informal knowledge of industry professions, such as rules of thumb and skills, must be observed by workers in the work environment so they acquire knowledge through comprehending empirical knowledge.

\section{Communication of safety knowledge:}

Communication is the process by which a supervisor or worker communicates opinions expressed by one party to another through a formal or informal communication channel. In addition to long-term accumulated knowledge in an organization, organization members are also required to contribute their knowledge for the sake of accumulation [34]. The sharing, interaction, and communication of members' safety knowledge within the organization will contribute to the flow of safety knowledge and learning applications. Supervisors conducting safety communication will also drive workers to demonstrate safety behaviors [32], improving their safety behaviors through effective communication [35,36]. Consistent sharing of safety information among employees helps to prevent on-site accidents. 
3. Application of safety knowledge:

This study named this concept safety knowledge application and inspiration. This means the application of safety knowledge (acquired through the acquisition and communication of safety knowledge) that enables workers to confirm the acquired knowledge in practical operations; and enables other personnel in the organization to acquire or receive the safety knowledge. Attempts by workers to apply their acquired knowledge within the organization allow the continuous dissemination of safety knowledge.

4. Acceptance of safety knowledge:

This study named this concept safety knowledge acceptance. When workers apply and accept the transferred knowledge, they obtain the knowledge required to prevent and eliminate accidents. Workers will clearly know what they should do as well as where and why when accidents occur, reducing the number of accidents caused by uncertainty [37].

5. Assimilation of safety knowledge:

The assimilation of safety knowledge is an individual's change in safety awareness and behaviors. This process allows an individual to be aware of the importance of safety, strengthens his or her awareness of safety, and thereby change his or her safety behaviors. This study named this concept safety concern and safety awareness.

Through conducting a literature review and extending Gilbert and Cordey-Hayes' knowledge transfer model [13], this study developed eight subconstructs, namely safety training, safety leadership, self-learning, safety knowledge communication, safety knowledge application and inspiration, safety knowledge acceptance, safety concern, and safety awareness, to indicate safety knowledge transfer (as shown in the dotted box in Figure 1). In the first four subconstructs (safety training, safety leadership, self-learning, and safety knowledge communication), an organization plays a crucial role in providing a proper environment for workers to acquire safety knowledge as well as appropriate channels for safety knowledge communication. These actions enable workers to apply the safety knowledge they acquire through the acquisition and communication of safety knowledge and inspire each other (safety knowledge application and inspiration). Additionally, these actions drive the acceptance and assimilation of safety knowledge (safety knowledge acceptance, safety concern, and safety awareness) for presenting specific safety behaviors. Therefore, this study defined the first four subconstructs as a safe knowledge transfer environment, emphasizing the importance of organizations providing an appropriate environment for initiating the transfer of safety knowledge. In addition, the latter three subconstructs were defined as safety behaviors.

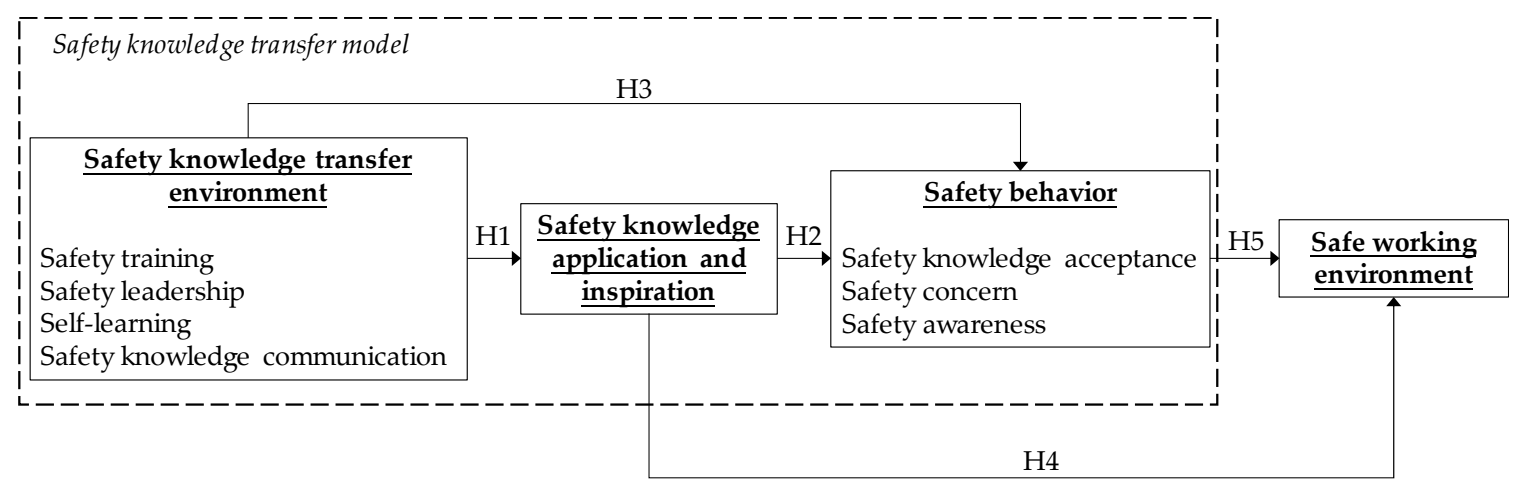

Figure 1. Diagram of the research hypotheses.

\subsection{Research Framework}

This study explored the constructs of a safe working environment and safety knowledge transfer model (safety knowledge transfer environment, safety knowledge application and inspiration, and 
safety behavior) presented in the previous section. A safe working environment is a place where all construction activities are conducted safely and workers have the working conditions they require to complete tasks safely. To prevent the occurrence of any accidents, a good on-site working environment is an essential ingredient. This study employed safety training, safety leadership, self-learning, and safety knowledge communication in response to the safety knowledge transfer environment, and safety knowledge acceptance, safety concern, and safety awareness in response to safety behaviors. In addition, to explore the effects of on-site safety knowledge transfer in a safe working environment, this study hypothesized that a safety knowledge transfer environment will affect safety behaviors and safety knowledge application and inspiration, which could lead to a safe working environment. Figure 1 presents the research hypotheses. According to the abovementioned discussion, this study proposed the following five hypotheses as shown in Table 1.

Table 1. Research hypotheses.

\begin{tabular}{|c|c|}
\hline Item & Hypothesis \\
\hline H1 & $\begin{array}{l}\text { A safety knowledge transfer environment has a positive effect on safety knowledge } \\
\text { application and inspiration. }\end{array}$ \\
\hline $\mathrm{H} 2$ & Safety knowledge application and inspiration have a positive effect on safety behavior. \\
\hline H3 & A safety knowledge transfer environment has a positive effect on safety behavior. \\
\hline $\mathrm{H} 4$ & $\begin{array}{c}\text { Safety knowledge application and inspiration have a positive effect on a safe working } \\
\text { environment. }\end{array}$ \\
\hline H5 & Safety behavior has a positive effect on a safe working environment. \\
\hline
\end{tabular}

\section{Methodology}

According to the research objectives and literature review, this study used statistical methods and SEM as research tools and applied empirical analysis to explore the correlation between construction-safety knowledge transfer and a safe working environment. On the basis of the literature review and an actual situation of on-site safety, this study drafted questionnaire items for each construct, discussed the definition of each item with practical experts, and confirmed the wording of sentences. A pretest of 50 samples [38] was performed prior to the issuance of the formal questionnaire to determine the reliability and goodness-of-fit of the questionnaire items.

Analysis results of the pretest were processed in four stages: (1) The correlation coefficient matrix of all items was calculated, and one of the two items with high correlation (the correlation coefficient exceeded 0.9) was eliminated. (2) An internal consistency indicator was used, and the sum of all the pretest samples was sorted in order; the difference between the top $27 \%$ (high-score group) and bottom $27 \%$ (low-score group) was used as the basis for item discrimination, and nondiscriminatory items were removed [39]. (3) Factor analysis was used to remove items with factor loadings less than 0.5 [40] to ensure the reliability and validity of the items. (4) The internal consistency of each construct was tested using the Cronbach's $\alpha$ value, where higher coefficient values indicate higher reliability.

This study used SEM and an empirical analysis to build an on-site safety knowledge transfer model for construction projects, and explored the relationship between on-site safety knowledge transfer and a safe working environment. SEM was proposed by scholars in the 1970s, and it combines the concept of path analysis with latent variables and factor analysis. In short, SEM integrates latent variables and observed variables, which forms the measurement model of SEM, and the structural model uses a path analysis model to study the causal relationship between latent variables; the integration of both models forms SEM.

When establishing SEM, the goodness-of-fit coefficient of the theoretical model should be judged. The higher the model's goodness-of-fit is, the more satisfactory the display model and the more meaningful the estimation parameters become. This study used the indexes listed in Table 2 as the measurement indicators, and composite reliability (CR) and average variance extracted (AVE) for 
testing [40-45]. According to Chin and Todd [45] and Hair et al. [40], the value of chi-square/degree of freedom $\left(\chi^{2} / \mathrm{df}\right)$ should not exceed 3 in rigorous research; thus, the judging criterion of $\chi^{2} / \mathrm{df}$ should be between 1 to 3. Doll et al. [44] indicated that goodness-of-fit index (GFI) and adjusted GFI (AGFI) range from 0.80 to 0.89 , which represent a reasonable goodness-of-fit of the model; therefore, the judging criteria of GFI and AGFI in this study had to exceed 0.9. The remaining indicators of normed fit index $(\mathrm{NFI})>0.90$, comparative fit index $(\mathrm{CFI})>0.9$, root mean square error of approximation (RMSEA) $<0.08$, and root mean square residual (RMR) $<0.05$ are often used as references for goodness-of-fit, which also served as the criteria for this study. Hair et al. [40] proposed that CR can be used to measure the internal consistency of indicator items of latent variables; the higher the CR value, the higher the consistency of the indicator items, with the suggested $C R$ value being $>0.7$. The AVE is the average explanatory power of the latent variables for each observation number. Bagozzi and Yi [41] proposed that the internal quality of a model is more favorable when the AVE is $>0.5$.

Table 2. Model fit indexes.

\begin{tabular}{cc}
\hline Index & Recommended Standards \\
\hline Chi-square/degree of freedom $\left(\chi^{2} / \mathrm{df}\right)$ & $<3$ \\
Goodness-of-fit index $(\mathrm{GFI})$ & $>0.9$ \\
Root mean square error of approximation (RMSEA) & $<0.08$ \\
Root mean square residual (RMR) & $<0.05$ \\
Adjusted GFI (AGFI) & $>0.9$ \\
Normed fit index (NFI) & $>0.9$ \\
Comparative fit index (CFI) & $>0.9$ \\
\hline
\end{tabular}

\section{Questionnaire Development and Distribution}

This study referred to relevant literature and held discussions with industry experts, such as construction site directors, occupational safety and health personnel, and on-site supervisors of architectural firms, to develop various construct items including safety training, safety leadership, safety communication, self-learning, safety knowledge application and inspiration, safety knowledge acceptance, safety concern, safety awareness, and a safe working environment. The initial questionnaire featured a total of 66 items. To measure participants' level of agreement on each item, they were measured using a five-point Likert scale ( $5=$ strongly agree, $4=$ agree, $3=$ neutral, $2=$ disagree, and $1=$ strongly disagree; the points for reversed items were from 1 (strongly agree) to 5 points (strongly disagree)).

Analysis results of the pretest questionnaires showed that the correlation coefficient values between the items were lower than 0.9 , indicating no similar items; thus, no items were removed. Regarding discriminant analysis, seven items that failed the analysis at a significance level of $10 \%$ were removed. Subsequently, factor analysis was performed for each construct, and nine items with a load factor less than 0.5 were eliminated. The formal questionnaire had a total of 50 items, as shown in Table 3. The Cronbach's $\alpha$ values of all constructs were greater than 0.7 , indicating that each construct had satisfactory reliability.

Participants in this study were on-site personnel in the construction industry in western Taiwan. A total of 311 questionnaires were distributed to construction site management personnel and workers, with a response rate of $78.14 \%$ (243 copies) and valid response rate of $66.24 \%$ (206 copies). Table 4 presents the basic information of the samples. The majority of the on-site personnel were aged between 26 and 35 years (38.3\%), followed by 36 to 45 years (33.5\%). A total of $62.6 \%$ of the on-site personnel had an undergraduate degree as their highest educational attainment. The majority had worked in the industry for fewer than 5 years (36.4\%), followed by 6 to 10 years (19.4\%) and 20 years and above $(17 \%)$. Most of the on-site personnel attended at least one safety training session per year $(83 \%)$, and most worked for a Level A construction company (73.3\%). In addition, most of the on-site personnel were engineers $(51.5 \%)$, followed by site directors (18.9\%). Finally, most of the on-site personnel had not encountered occupational accidents on site within the last 3 years $(67.5 \%)$. 
Table 3. Factor analysis results and Cronbach's $\alpha$ values of each construct.

\begin{tabular}{|c|c|c|}
\hline Construct (Cronbach's $\alpha$ ) & Item & Factor Load \\
\hline \multirow{6}{*}{ Safety Training (0.803) } & $\begin{array}{l}\text { T1: Current on-site supervisors often organize routine occupational } \\
\text { health and safety training courses. }\end{array}$ & 0.662 \\
\hline & $\begin{array}{l}\text { T2: Current on-site supervisors often train workers on how to work } \\
\text { safely and comply with safety regulations. }\end{array}$ & 0.826 \\
\hline & $\begin{array}{c}\text { T3: Current on-site supervisors rarely train workers on proper safety } \\
\text { behaviors and attitudes. }\end{array}$ & 0.646 \\
\hline & $\begin{array}{l}\text { T4: Current on-site supervisors often discuss with workers to review } \\
\text { and improve dangerous workplace situations. }\end{array}$ & 0.763 \\
\hline & $\begin{array}{l}\text { T5: Current on-site supervisors often encourage workers to express } \\
\text { ideas and recommendations on safety issues. }\end{array}$ & 0.746 \\
\hline & $\begin{array}{l}\text { T6: Current on-site supervisors regularly ask colleagues to pay more } \\
\text { attention to the safety awareness of new workers. }\end{array}$ & 0.697 \\
\hline \multirow{6}{*}{ Safety Leadership (0.899) } & $\begin{array}{l}\text { L1: Current on-site supervisors often guide workers to be cautious and } \\
\text { strictly follow safety procedures. }\end{array}$ & 0.648 \\
\hline & $\begin{array}{l}\text { L2: Current on-site supervisors emphasize the company's belief that } \\
\text { safety and work are equally crucial. }\end{array}$ & 0.591 \\
\hline & $\begin{array}{l}\text { L3: Current on-site supervisors promptly remind workers who have } \\
\text { incorrect concepts regarding safety. }\end{array}$ & 0.743 \\
\hline & $\begin{array}{l}\text { L4: Current on-site supervisors often remind me of safety issues that } \\
\text { should be noted at work. }\end{array}$ & 0.665 \\
\hline & $\begin{array}{c}\text { L5: My supervisor often leads by example to actively share safety } \\
\text { knowledge. }\end{array}$ & 0.688 \\
\hline & $\begin{array}{l}\text { L6: Current on-site supervisors immediately correct workers who do } \\
\text { not comply with safety regulations. }\end{array}$ & 0.682 \\
\hline \multirow{3}{*}{ Self-learning (0.808) } & SL1: I often try to apply safety knowledge to the construction site. & 0.818 \\
\hline & SL2: I often share my safety knowledge. & 0.754 \\
\hline & $\begin{array}{l}\text { SL3: I often learn work safety from the contents of the health and safety } \\
\text { management section of the construction plan. }\end{array}$ & 0.638 \\
\hline \multirow{4}{*}{$\begin{array}{l}\text { Safety Knowledge } \\
\text { Communication (0.752) }\end{array}$} & $\begin{array}{l}\text { C1: On-site supervisors can provide appropriate guidance and } \\
\text { solutions to colleagues who face any safety problems. } \\
\text { C2: On-site supervisors value proposals or recommendations related to } \\
\text { accident prevention. }\end{array}$ & $\begin{array}{l}0.622 \\
0.678\end{array}$ \\
\hline & $\begin{array}{l}\text { C3: On-site supervisors often raise safety-related issues during } \\
\text { meetings. }\end{array}$ & 0.704 \\
\hline & $\begin{array}{l}\text { C4: I often convert safety knowledge into text and store it in a shared } \\
\text { folder in an electronic file. }\end{array}$ & 0.541 \\
\hline & C5: I often learn about work safety by chatting with colleagues. & 0.553 \\
\hline \multirow{6}{*}{$\begin{array}{l}\text { Safety Knowledge } \\
\text { Application and Inspiration } \\
(0.828)\end{array}$} & AI1: I inform my superiors when I notice any unsafe behavior. & 0.624 \\
\hline & AI2: I inform everyone when I receive a new company safety policy. & 0.753 \\
\hline & AI3: I often pass on safety knowledge to other people at the scene. & 0.782 \\
\hline & AI4: I do not often share accident cases with other people at the scene. & 0.534 \\
\hline & AI5: I often solve the safety concerns of my colleagues or workers. & 0.776 \\
\hline & AI6: I think that individuals affect each other in terms of safety behavior. & 0.909 \\
\hline \multirow{5}{*}{$\begin{array}{l}\text { Safety Knowledge } \\
\text { Acceptance (0.722) }\end{array}$} & A1: I understand the accidents that I may encounter at work. & 0.538 \\
\hline & A2: I usually use tools, utensils, and materials correctly. & 0.572 \\
\hline & $\begin{array}{l}\text { A3: I understand all approaches and regulations on the use of personal } \\
\text { protective equipment. }\end{array}$ & 0.576 \\
\hline & A4: I understand the safety risks posed by unsafe actions. & 0.511 \\
\hline & A5: I always remember construction-safety knowledge. & 0.686 \\
\hline \multirow{4}{*}{ Safety Concern (0.790) } & SC1: I check and confirm that it is safe to start work. & 0.691 \\
\hline & $\begin{array}{l}\text { SC2: When I notice any unsafe behavior during work, I stop work and } \\
\text { eliminate it. }\end{array}$ & 0.781 \\
\hline & $\begin{array}{c}\text { SC3: I correct my colleagues or workers immediately if I notice they are } \\
\text { behaving unsafely. }\end{array}$ & 0.784 \\
\hline & $\begin{array}{l}\text { SC4: I not only pay attention to my own safety but also to that of my } \\
\text { colleagues. }\end{array}$ & 0.742 \\
\hline
\end{tabular}


Table 3. Cont

\begin{tabular}{|c|c|c|}
\hline Construct (Cronbach's $\alpha$ ) & Item & Factor Load \\
\hline \multirow{4}{*}{ Safety Awareness (0.726) } & SA1: I restore or maintain dismantled safety protection equipment. & 0.502 \\
\hline & SA2: I still continue to work when I fall sick. & 0.804 \\
\hline & SA3: I pay special attention to construction safety when the project is rushed. & 0.606 \\
\hline & SA4: I do not propose discussions when I have any safety-related suggestions. & 0.723 \\
\hline \multirow{11}{*}{$\begin{array}{l}\text { Safe Working Environment } \\
\qquad(0.916)\end{array}$} & E1: The site has an excellent safety management system. & 0.705 \\
\hline & E2: Safety warning signs can be found everywhere on the construction site. & 0.771 \\
\hline & E3: The on-site personnel is always alert in the work environment at all times. & 0.703 \\
\hline & E4: A guardrail will be added to areas in a workplace where it is easy to fall. & 0.768 \\
\hline & E5: All holes in the workplace will be covered. & 0.690 \\
\hline & E6: Illumination of the workplace is extremely inadequate. & 0.805 \\
\hline & E7: All fire safety equipment in the workplace is adequately set up. & 0.768 \\
\hline & E8: Workers have appropriate safety equipment when working at heights. & 0.781 \\
\hline & E9: Water is sprinkled when there is excessive dust. & 0.661 \\
\hline & E10: Everyone wears protective equipment when there is excessive dust. & 0.618 \\
\hline & E11: Safety of the site is reviewed daily before work. & 0.637 \\
\hline
\end{tabular}

Table 4. Basic information distribution of the samples.

\begin{tabular}{|c|c|c|c|}
\hline Variable & Category & Number & Percentage \\
\hline \multirow{2}{*}{ Gender } & Male & 180 & $87.4 \%$ \\
\hline & Female & 26 & $12.6 \%$ \\
\hline \multirow{5}{*}{ Age } & Below 25 years & 14 & $6.8 \%$ \\
\hline & 26-35 years & 79 & $38.3 \%$ \\
\hline & $36-45$ years & 69 & $33.5 \%$ \\
\hline & $46-55$ years & 39 & $18.9 \%$ \\
\hline & 56 years and above & 5 & $2.4 \%$ \\
\hline \multirow{4}{*}{$\begin{array}{c}\text { Highest educational level } \\
\text { obtained }\end{array}$} & Below junior high school & 6 & $2.9 \%$ \\
\hline & High school & 34 & $16.5 \%$ \\
\hline & Undergraduate & 129 & $62.6 \%$ \\
\hline & Postgraduate and above & 37 & $18.0 \%$ \\
\hline \multirow{5}{*}{$\begin{array}{l}\text { Years of working experience in } \\
\text { the construction industry }\end{array}$} & Below 5 years & 75 & $36.4 \%$ \\
\hline & 6-10 years & 40 & $19.4 \%$ \\
\hline & $11-15$ years & 26 & $12.6 \%$ \\
\hline & 16-20 years & 30 & $14.6 \%$ \\
\hline & 20 years and above & 35 & $17.0 \%$ \\
\hline \multirow{5}{*}{$\begin{array}{l}\text { Number of safety training } \\
\text { events attended in the past year }\end{array}$} & 0 & 35 & $17.0 \%$ \\
\hline & 1 & 83 & $40.3 \%$ \\
\hline & 2 & 34 & $16.5 \%$ \\
\hline & 3 & 23 & $11.2 \%$ \\
\hline & 3 and above & 31 & $15.0 \%$ \\
\hline \multirow{4}{*}{$\begin{array}{l}\text { Grade of the general } \\
\text { construction business }\end{array}$} & Level A & 151 & $73.3 \%$ \\
\hline & Level B & 16 & $7.8 \%$ \\
\hline & Level C & 14 & $6.8 \%$ \\
\hline & Others & 25 & $12.1 \%$ \\
\hline \multirow{5}{*}{ On-site position } & Worker & 25 & $12.1 \%$ \\
\hline & Engineer & 106 & $51.5 \%$ \\
\hline & Management personnel & 24 & $11.7 \%$ \\
\hline & Site director & 39 & $18.9 \%$ \\
\hline & Others & 12 & $5.8 \%$ \\
\hline
\end{tabular}




\section{Results and Analysis}

\subsection{Measurement Model Test Results}

This section describes how this study used SEM to verify the causal relationships between variables. The correlations between knowledge transfer environment (safety training, safety leadership, safety knowledge communication, and self-learning), safety knowledge application and inspiration, and safety behaviors (safety knowledge acceptance, safety concern, and safety awareness) were explored.

This study first analyzed the measurement model and verified whether the goodness-of-fit of each construct of the model was acceptable. If it was not acceptable, the items were removed to modify the model. The evaluation indicators of $\chi^{2} / \mathrm{df}, \mathrm{GFI}, \mathrm{AGFI}, \mathrm{RMSEA}, \mathrm{RMR}, \mathrm{NFI}$, and CFI were used as the basis for judging whether the measurement model had a good fit, and the AVE and CR were used for testing. After eliminating T1, T2, L1, L2, C4, SA1, SA3, A4, AI4, AI5, E1, E3, E4, E6, and E11, each construct met all fit indicators with the recommended standards in Table 2 (Table 5). As shown in Table 6 , the CR of each construct was $>0.7$, indicating their adequate reliability. The AVE values of each construct were all $>0.5$, demonstrating that each had adequate convergent validity.

Table 5. Goodness-of-fit of the measurement model and the structural model.

\begin{tabular}{|c|c|c|c|c|c|}
\hline \multirow[b]{2}{*}{ Index } & \multicolumn{4}{|c|}{ Construct of the Measurement Model } & \multirow[b]{2}{*}{$\begin{array}{c}\text { Structural } \\
\text { Model }\end{array}$} \\
\hline & $\begin{array}{c}\text { Safety Knowledge } \\
\text { Transfer } \\
\text { Environment }\end{array}$ & $\begin{array}{l}\text { Safety Knowledge } \\
\text { Application and } \\
\text { Inspiration }\end{array}$ & $\begin{array}{c}\text { Safety } \\
\text { Behavior }\end{array}$ & $\begin{array}{l}\text { Safe Working } \\
\text { Environment }\end{array}$ & \\
\hline$\chi^{2} / \mathrm{df}$ & 1.223 & 1.039 & 1.648 & 2.241 & 1.134 \\
\hline GFI & 0.941 & 0.990 & 0.953 & 0.940 & 0.927 \\
\hline RMSEA & 0.033 & 0.014 & 0.056 & 0.078 & 0.026 \\
\hline RMR & 0.021 & 0.013 & 0.029 & 0.034 & 0.260 \\
\hline AGFI & 0.910 & 0.969 & 0.918 & 0.900 & 0.902 \\
\hline NFI & 0.945 & 0.985 & 0.930 & 0.922 & 0.919 \\
\hline CFI & 0.989 & 0.999 & 0.971 & 0.955 & 0.990 \\
\hline
\end{tabular}

Table 6. CR and AVE for each construct of the measurement model.

\begin{tabular}{ccc}
\hline Construct & CR & AVE \\
\hline Safety knowledge transfer environment & 0.9364 & 0.7873 \\
Safety knowledge application and inspiration & 0.837 & 0.5677 \\
Safety behavior & 0.7885 & 0.5790 \\
Safe working environment & 0.8573 & 0.5083 \\
\hline
\end{tabular}

\subsection{Structural Model Test Results}

According to the proposed research hypotheses, the structural model between each construct was established and a path analysis was performed. Figure 2 illustrates the final structural model of this study. The index of the adjusted structural model achieved the following results; $\chi^{2} / \mathrm{df}=1.134$, $\mathrm{GFI}=0.927$, RMSEA $=0.026$, RMR $=0.260$, AGFI $=0.902, \mathrm{NFI}=0.919$, and CFI $=0.990$, as shown in Table 5. The overall fit statistics indicated an excellent fit for the model; thus, the results supported the hypothesized relationship.

Hypothesis testing was performed according to the results of models empirically presented in this study. H1 was that a knowledge transfer environment has a positive and significant effect on safety knowledge application and inspiration. The path coefficient of knowledge transfer environment to safety knowledge application and inspiration was $0.874(p<0.001)$; thus, H1 was supported, indicating that an improved knowledge transfer environment can result in greater safety knowledge application and inspiration of on-site workers. H3 posited that a knowledge transfer environment has a positive and significant effect on safety behavior. The path coefficient of knowledge transfer environment to safety behavior was 0.587 ( $p<0.001)$; thus, H3 was supported, indicating that a more satisfactory 
knowledge transfer environment will drive on-site workers to demonstrate higher levels of safety behavior. $\mathrm{H} 2$ posited that safety knowledge application and inspiration have a positive and significant effect on safety behavior. The path coefficient of safety knowledge application and inspiration to safety behavior was $0.440(p<0.01)$; thus, $\mathrm{H} 2$ was supported, signifying that greater safety knowledge application and inspiration of on-site workers can lead to improved safety behavior. Moreover, this showed that, in addition to directly affecting safety behaviors, the knowledge transfer environment indirectly affects safety behaviors through safety knowledge application and inspiration. H5 posited that safety behavior has a positive and significant effect on a safe working environment. The path coefficient of personal safety behavior to safe working environment was $0.795(p<0.001)$; thus, H5 was supported, indicating that the working environment of a construction site is safer when on-site workers exhibit more safety behaviors. In the case of a safe working environment, a higher chance exists for preventing on-site accidents.

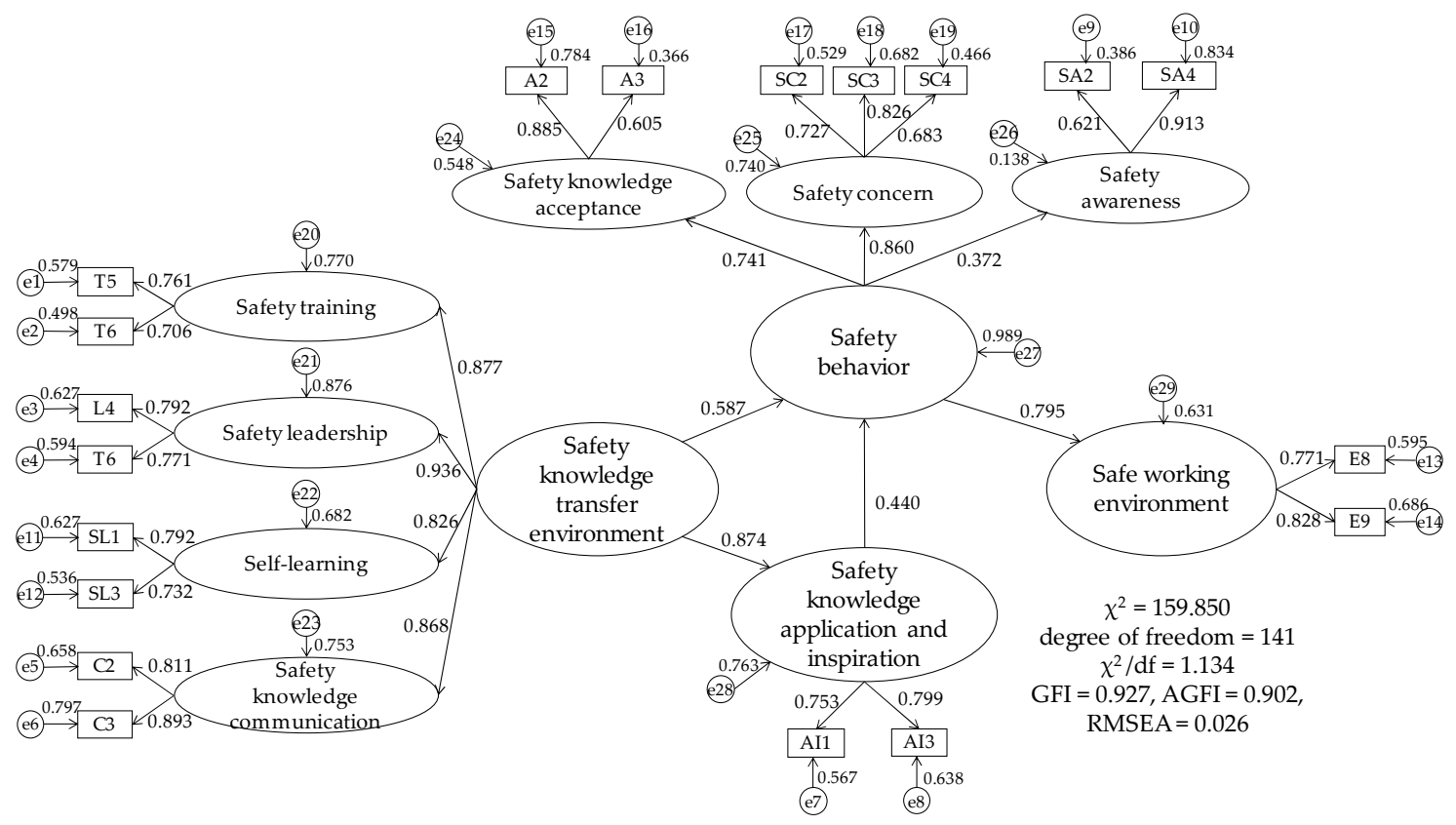

Figure 2. Overall structural model.

$\mathrm{H} 4$ posited that safety knowledge application and inspiration have a positive and significant effect on a safe working environment; however, as shown in Figure 2, safety knowledge application and inspiration did not directly affect safe working environment. By contrast, because $\mathrm{H} 2$ and $\mathrm{H} 5$ were supported, safety knowledge application and inspiration indirectly affect safe working environment through safety behaviors; this means that $\mathrm{H} 4$ should be supported because safety knowledge application and inspiration have a positive and significant effect on safe working environment. Table 7 presents the direct and indirect effects of latent independent variables of the overall model on latent dependent variables. Among the total effects, the knowledge transfer environment had the greatest effect on safety behavior, and safety knowledge application and inspiration had the smallest effect on safe working environment. Path values in the structural model were positive, indicating that the various constructs are positively related. Knowledge transfer environment and safety knowledge application and inspiration indirectly affected a safe working environment through safety behavior in a positive and increasing trend. 
Table 7. Effects of the overall model.

\begin{tabular}{|c|c|c|c|c|c|}
\hline $\begin{array}{c}\text { Latent Independent } \\
\text { Variable }\end{array}$ & $\begin{array}{l}\text { Latent Dependent } \\
\text { Variable }\end{array}$ & Direct Effect & Indirect Effect & Total Effect & $\begin{array}{l}\text { Hypothesis } \\
\text { Supported? }\end{array}$ \\
\hline \multirow[t]{2}{*}{$\begin{array}{c}\text { Safety knowledge transfer } \\
\text { environment }\end{array}$} & $\begin{array}{l}\text { Safety knowledge } \\
\text { application and } \\
\text { inspiration }\end{array}$ & 0.874 & - & 0.874 & H1 was supported \\
\hline & Safety behavior & 0.587 & $0.874 \times 0.44=0.385$ & 0.972 & H3 was supported \\
\hline \multirow{2}{*}{$\begin{array}{c}\text { Safety knowledge } \\
\text { application and inspiration }\end{array}$} & Safety behavior & 0.440 & - & 0.440 & H2 was supported \\
\hline & $\begin{array}{l}\text { Safe working } \\
\text { environment }\end{array}$ & - & $0.44 \times 0.795=0.350$ & 0.350 & H4 was supported \\
\hline Safety behavior & $\begin{array}{l}\text { Safe working } \\
\text { environment }\end{array}$ & 0.795 & - & 0.795 & H5 was supported \\
\hline
\end{tabular}

\section{Discussion}

The knowledge transfer environment constructs included four subconstructs: safety training, safety leadership, safety knowledge communication, and self-learning. Among them, safety leadership had the highest factor loading (0.936), which was the most vital factor in the knowledge transfer environment, followed by safety training (0.877), safety knowledge communication (0.868), and self-learning (0.826). On-site supervisors often remind workers to pay attention to safety and immediately correct unsafe behaviors on the spot, resulting in the effect of safety leadership. Safety training is improved when on-site supervisors encourage workers to express safety concerns or regularly ask their colleagues to pay more attention to the safety of new workers. Furthermore, safety knowledge communication will be enhanced when on-site supervisors emphasize proposals or suggestions for accident prevention, as well as frequently discuss safety-related topics. In addition, applying safety knowledge to the on-site construction environment for confirming knowledge and understanding safety hazards at work through an organization's health and safety management plan can be regarded as self-learning performance. In addition to safety leadership, on-site supervisors play an essential role in safety training and safety knowledge communication. This shows that the safety concerns of on-site supervisors are vital for establishing workers' safety knowledge. The results of this study indicated that safety knowledge acquisition and self-learning orientation of Taiwan's construction workers are relatively passive, where the workers acquire safety knowledge through safety training and communication provided by their on-site supervisors as opposed to them learning them on their own.

Safety behavior constructs included safety knowledge acceptance, safety concern, and safety awareness. Among them, safety concern had the highest factor loading $(0.860)$, indicating that it was the most crucial factor affecting safety behaviors (i.e., individuals who are more concerned with safety tend to exhibit higher levels of safety behavior), followed by safety knowledge acceptance (0.741), with the lowest being safety awareness (0.372). This result indicated that on-site workers should strengthen links between safety awareness and safety behavior. In terms of the acceptance of safety knowledge, most of the on-site workers could use tools, equipment, or materials correctly, and could understand the use and regulations of personal protective equipment, indicating that they possessed a certain amount of safety knowledge. Safety concern is reflected in on-site workers stopping work to eliminate the unsafe behaviors of others, indicating that they do not only pay attention to their own safety at work. On-site workers' safety awareness can be improved by enhancing their perceptions of their bodies, having them understand that they should stop working whenever they experience physical discomfort, and having them raise their own concerns about on-site safety. Safety knowledge application and inspiration can affect safety behaviors. Therefore, applying acquired safety knowledge to unsafe behaviors at work and informing management, or passing safety knowledge on to others, can directly affect the safety behaviors of on-site workers and indirectly make the work environment safer.

According to the aforementioned analysis, effective improvements of safety knowledge transfer are necessary for a safe working environment, which can be achieved through safety training, safety leadership, safety knowledge communication, and self-learning. On-site supervisors should encourage 
workers to express their thoughts and suggestions on safety issues, regularly ask their colleagues to pay more attention to new workers' safety awareness, and counsel and encourage workers to participate in safety issues to improve the effects of safety knowledge transfer. Furthermore, the leadership method of on-site management personnel has a great effect on knowledge transfer; if they emphasize safety, they will deliver safety knowledge to others. For example, on-site supervisors should often remind workers of safety issues to pay attention to at work. Moreover, supervisors should immediately correct workers' behavior in accordance with safety regulations. Such an active and positive leadership method can effectively transfer knowledge. Pu et al. (2013) noted that leaders with high levels of care or control can effectively control the unsafe behaviors of workers; workers' safety behaviors can be developed easily if the leadership behavior of on-site personnel has a more apparent development.

Moreover, the communication of on-site management personnel is critical. For instance, on-site supervisors should emphasize accident prevention-related proposals or suggestions, regularly raise safety-related topics in meetings, and be willing to discuss safety prevention with other workers. Regardless of whether the content discussed will be accepted, results must be obtained from discussions and idea exchange between management personnel and workers. Furthermore, management personnel must provide warnings about the unsafe behavior they have noticed to improve safety knowledge communication and safety prevention.

On-site knowledge transfer is not limited to management personnel; workers must also acquire safety knowledge by themselves, such as attempting to apply safety knowledge to their construction site and learning work safety from the health and safety management plan. To acquire knowledge, workers must not wait for it to be imparted by others but also identify their own sources of knowledge through observing, imitating, and reading. Applying the knowledge acquired on-site that enables other workers to learn and follow, and teaching workers of accidents that may occur can achieve mutual vigilance and influence, thereby reducing accidents.

Successful knowledge transfer requires people to impart and receive knowledge. Knowledge possessed by each individual is not necessarily similar. Therefore, a knowledge consensus can be achieved through mutual exchange, presentation, and discussion, which means that everyone is a seed of knowledge, and effective knowledge dissemination can turn it into a normal cycle. Safety in on-site construction environments can only be achieved when knowledge is transferred continuously in a cycle.

\section{Conclusions}

This study constructed a safety knowledge transfer model and explored the relationship between safety knowledge transfer and safe working environments. The safety knowledge transfer model included knowledge transfer environment (safety training, safety leadership, safety knowledge communication, and self-learning), safety knowledge application and inspiration, and safety behaviors (safety knowledge acceptance, safety concern, and safety awareness) in response to the processes of acquisition, communication, application, acceptance, and assimilation of transferred knowledge. After the structural model was established using SEM, hypothesis testing was performed. With the significance level set at 95\%, all hypotheses in Table 1 reached significance, indicating that the working environment at a construction site is safer when the degree of knowledge transfer is higher. The knowledge transfer environment affects the safety behaviors of on-site workers as well as their safety knowledge application and inspiration. Furthermore, safety behaviors are affected by the safety knowledge application and inspiration of other personnel. The on-site working environment is directly and indirectly affected by safety behaviors and safety knowledge application and inspiration, respectively, improving the safety of the site.

The path values of each path could be determined after structural model analysis was performed. The total effects of each path value were knowledge transfer environment to safety behavior (0.972), knowledge transfer environment to safety knowledge application and inspiration (0.874), safety knowledge application and inspiration to safety behavior (0.440), safety knowledge application and 
inspiration to safe working environment (0.350), and safety behavior to safe working environment (0.795). Safety behaviors may change because of the knowledge transfer of on-site workers, such as on-site supervisors encouraging workers to express their ideas and suggestions on safety issues, immediately correcting workers' unsafe behaviors, and raising safety-related issues in meetings, as well as on-site workers applying safety knowledge to the construction site, which will result in safety knowledge transfer and changes in safety behaviors of the workers. Once safety behaviors are improved, on-site workers will pay attention to matters such as correctly using tools and protective equipment, stopping work and eliminating unsafe behaviors when they notice them, and stopping work when they experience physical discomfort. The improvement of safety behaviors can enhance safe on-site working environments.

In summary, safety-related knowledge transfer must be practiced to improve the safety of on-site work environments. Increasing the safety knowledge of on-site workers through meetings, on-site teaching, and safety-related issues can improve their appreciation of the importance of protective equipment. Moreover, on-site workers will pay more attention to the safety of themselves and others. This study's research model showed that safety behavior and safety knowledge application and inspiration mediated the effect of the knowledge transfer environment on the safe working environment, indicating the importance of on-site knowledge transfer. A safe working environment can be formed if on-site management personnel can transfer safety knowledge to on-site workers and cultivate it, provide guidance to them, ask for relevant safety opinions, always pay attention to and correct workers' safety problems, and correctly apply safety knowledge. Therefore, on-site management personnel must emphasize knowledge transfer, whether through education and training, on-site communication and guidance, and listening to the opinions of on-site workers. In addition, this study revealed that the linkage between the safety awareness and safety behavior of on-site workers was weak; therefore, strengthening it should be a focus in safety knowledge transfer.

According to the discussion in this study, several recommendations and future research directions were proposed. This study only used four subconstructs (i.e., safety training, safety leadership, safety communication, and self-learning) to represent a knowledge transfer environment, and assumed that each subconstruct was independent. Subsequent research can continue to explore the effectiveness of on-site workers' knowledge transfer and the correlation between each subconstruct, as well as develop a knowledge transfer effectiveness scale for on-site workers in the construction industry to understand the pros and cons of knowledge transfer, on the basis of which the knowledge transfer model can be revised. The participants of this study were on-site personnel in the construction industry. Future research can further investigate differences between the various levels of personnel, such as on-site construction workers, middle management personnel (on-site construction management personnel), and senior management personnel (supervisors). Because the cultures of different countries differ, further discussions and comparisons between the construction industries of different countries are warranted.

Author Contributions: Conceptualization, Y.-H.H. and T.-R.Y.; data curation, Y.-H.H.; formal analysis, T.-R.Y.; investigation, T.-R.Y.; methodology, Y.-H.H. and T.-R.Y.; project administration, Y.-H.H.; writing—original draft, Y.-H.H.; writing—review and editing, Y.-H.H.

Funding: This research received no external funding.

Acknowledgments: The authors would like to express their sincere gratitude to the anonymous reviewers who significantly enhanced the contents of the study with their insightful comments.

Conflicts of Interest: The authors declare no conflict of interest.

\section{References}

1. Occupational Safety and Health Administration. 2018 Labor Inspection Annual Report; Occupational Safety and Health Administration: Ministry of Labor: Taipei, Taiwan, 2019. (In Chinese)

2. Cheng, C.W.; Leu, S.S.; Lin, C.C.; Fan, C. Characteristic analysis of occupational accidents at small construction enterprises. Saf. Sci. 2010, 48, 698-707. [CrossRef] 
3. Chi, C.F.; Yang, H.S.; Chen, W.S.; Liu, K.C.; Chang, T.C.; Ting, H.I. In-depth analysis and prevention of fatal falls in construction industry. J. Occup. Saf. Health 2008, 16, 383-400. (In Chinese)

4. Musonda, I.; Smallwood, J. Health and safety (H\&S) awareness and implementation in Botswana's construction industry. J. Eng. Des. Technol. 2008, 6, 81-90.

5. Chen, W.T.; Lu, C.S.; Huang, Y.H. Investigating the safety cognition of Taiwan's construction personnel. J. Mar. Sci. Technol. 2011, 19, 398-408.

6. Leu, S.S.; Chang, C.M. Bayesian-network-based safety risk assessment for steel construction projects. Accid. Anal. Prev. 2013, 54, 122-133. [CrossRef] [PubMed]

7. Nadhim, E.A.; Hon, C.K.; Xia, B.; Stewart, I.; Fang, D. Investigating the relationships between safety climate and safety performance indicators in retrofitting works. Constr. Econ. Build. 2018, 18, 110-129. [CrossRef]

8. Teo, E.A.L.; Ling, F.Y.Y.; Chong, A.F.W. Framework for project managers to manage construction safety. Int. J. Proj. Manag. 2005, 23, 329-341. [CrossRef]

9. Heinrich, H. Industrial Accident Prevention, 4th ed.; Mc Graw-Hill Book Company: New York, NY, USA, 1959.

10. Cheng, C.W.; Leu, S.S.; Cheng, Y.M.; Wu, T.C.; Lin, C.C. Applying data mining techniques to explore factors contributing to occupational injuries in Taiwan's construction industry. Accid. Anal. Prev. 2012, 48, 214-222. [CrossRef]

11. Geller, E.S. Ten principles for achieving a total safety culture. Prof. Saf. 1994, 9, 18-24.

12. Nonaka, I. A dynamic theory of organizational knowledge creation. Organ. Sci. 1994, 5, 14-37. [CrossRef]

13. Gilbert, M.; Cordey-Hayes, M. Understanding the process of knowledge transfer to achieve successful technological innovation. Technovation 1996, 16, 301-312. [CrossRef]

14. Spiegler, I. Knowledge management: A new idea or a recycled concept? Commun. Assoc. Inf. Syst. 2000, 3 , 14. [CrossRef]

15. Nancy, M.D. Common Knowledge: How Companies Thrive by Sharing What They Know; Harvard Business School Press: Boston, MA, USA, 2000.

16. Davenport, T.H.; Prusak, L. Working Knowledge: How Organizations Manage What They Know; Harvard Business School Press: Boston, MA, USA, 1998.

17. Polanyi, M.; Sen, A. The Tacit Dimension; University of Chicago Press: Chicago, IL, USA, 2009.

18. Nonaka, I.; Takeuchi, H. The Knowledge-Creating Company; Oxford University Press: Oxford, UK, 1955.

19. Szulanski, G. Exploring internal stickiness: Impediments to the transfer of best practice within the firm. Strateg. Manag. J. 1996, 17, 27-43. [CrossRef]

20. Verkasalo, M.; Lappalainen, P. A method of measuring the efficiency of the knowledge utilization process. IEEE Trans. Eng. Manag. 1998, 45, 414-423. [CrossRef]

21. Wiig, K.M. Integrating intellectual capital and knowledge management. Long Range Plan. 1997, 30, $399-405$. [CrossRef]

22. Zhang, S.; Boukamp, F.; Teizer, J. Ontology-based semantic modeling of construction safety knowledge: Towards automated safety planning for job hazard analysis (JHA). Autom. Constr. 2015, 52, 29-41. [CrossRef]

23. Hadikusumo, B.H.W.; Rowlinson, S. Capturing safety knowledge using design-for-safety-process tool. J. Constr. Eng. Manag. 2004, 130, 281-289. [CrossRef]

24. Neal, A.; Griffin, M.A.; Hart, P.M. The impact of organizational climate on safety climate and individual behavior. Saf. Sci. 2000, 34, 99-109. [CrossRef]

25. Li, R.Y.M.; Chau, K.W.; Lu, W.; Ho, D.C.W.; Shoaib, M.; Meng, L. Construction hazard awareness and construction safety knowledge sharing epistemology. In Proceedings of the International Conference on Smart Infrastructure and Construction 2019 (ICSIC): Driving Data-Informed Decision-Making, Churchill College, Cambridge, UK, 8-10 July 2019; pp. 283-290.

26. Taher, A.; Vahdatikhaki, F.; Hammad, A. Integrating earthwork ontology and safety regulations to enhance operations safety. In Proceedings of the 36th International Symposium on Automation and Robotics in Construction (ISARC), Banff, AB, Canada, 21-24 May 2019.

27. Le, Q.T.; Pedro, A.; Park, C.S. A social virtual reality based construction safety education system for experiential learning. J. Intell. Robot. Syst. 2015, 79, 487-506. [CrossRef]

28. Jeelani, I.; Albert, A.; Gambatese, J.A. Why do construction hazards remain unrecognized at the work interface? J. Constr. Eng. Manag. 2017, 143, 4016128. [CrossRef]

29. Shin, M.; Lee, H.-S.; Park, M.; Moon, M.; Han, S. A system dynamics approach for modeling construction workers' safety attitudes and behaviors. Accid. Anal. Prev. 2014, 68, 95-105. [CrossRef] [PubMed] 
30. Blair, E. Culture and leadership: Seven key points for improved safety performance. Prof. Saf. 2003, 48, $18-22$.

31. Hofmann, D.A.; Morgeson, P. Safety-related behavior as a social exchange: The role of perceived organizational support and leader-member exchange. J. Appl. Psychol. 1999, 84, 286-296. [CrossRef]

32. Tsaur, C.C.; Lin, S.H.; Kuo, C.C.; Gau, C.Y. The safety leadership and communication of supervisors and the safety behavior of workers: The moderating effect of safety management. J. Occup. Saf. Health 2012, 20, 1-33. (In Chinese)

33. O'Dea, A.; Flin, R. Site managers and safety leadership in the offshore oil and gas industry. Saf. Sci. 2001, 37, 39-57. [CrossRef]

34. Simon, M. The Creative Marketer; Butterworth-Heinemann Ltd.: London, UK, 1991.

35. Ojanen, K.; Seppälä, A.; Aaltonen, M. Measurement methodology for the effects of accident prevention programs. Scand. J. Work Environ. Health 1988, 14, 95-96.

36. Holt, A.S.J. Principles of Construction Safety; Blackwell Science: London, UK, 2001.

37. Smith-Crowe, K.; Burke, M.J.; Landis, R.S. Organizational climate as a moderator of safety knowledge safety performance relationships. J. Organ. Behav. 2003, 24, 861-876. [CrossRef]

38. Fowler, F.J., Jr. Survey Research Methods; Sage: Thousand Oaks, CA, USA, 2013.

39. Cureton, E.E. The upper and lower twenty-seven percent rule. Psychometrika 1957, 22, 293-296. [CrossRef]

40. Hair, J.F.; Black, B.; Brain, B.; Anderson, R.E.; Tatham, R.L. Multivariate Data Analysis, 6th ed.; Prentice Hall: Upper Saddle River, NJ, USA, 2006.

41. Bagozzi, R.P.; Yi, Y. On the evaluation for structural equation models. J. Acad. Mark. Sci. 1998, 16, 74-94. [CrossRef]

42. Bentler, P.M. Comparative fit indexes in structural models. Psychol. Bull. 1990, 107, 238-246. [CrossRef]

43. Bentler, P.M. On the fit of models to covariances and methodology to the Bulletin. Psychol. Bull. 1992, 112, 400-404. [CrossRef] [PubMed]

44. Doll, W.J.; Xia, W.; Torkzadeh, G. A confirmatory factor analysis of the end-user computing satisfaction instrument. MIS Q. 1994, 18, 453-461. [CrossRef]

45. Chin, W.W.; Todd, P.A. On the use, usefulness, and ease of use of structural equation modeling in MIS research: A note of caution. MIS Q. 1995, 19, 237-246. [CrossRef] 